Short communication

\title{
Renal effects of Bunodosoma caissarum crude extract: Prostaglandin and endothelin involvement
}

\author{
René Duarte Martins ${ }^{a}$, Roberta Jeane Bezerra Jorge ${ }^{a,}{ }^{*}$, Renata de Sousa Alves ${ }^{b}$, \\ Antônio Gomes da Silva Neto ${ }^{c}$, Paulo Sergio F. Barbosa ${ }^{\mathrm{d}}$, Alice Maria Costa Martins ${ }^{\mathrm{b}}$, \\ Marcos H. Toyama ${ }^{\mathrm{e}}$, Helena Serra Azul Monteiro ${ }^{\mathrm{c}}$ \\ a Department of Nutrition, Federal University of Pernambuco, CAV, Vitória de Santo Antão, Pernambuco, Brazil \\ b Department of Clinical and Toxicological Analyses, Federal University of Ceará, Fortaleza, Ceará, Brazil \\ c Department of Physiology and Pharmacology, Institute of Biomedicine and Clinical Research Unit, Federal University of Ceará, Fortaleza, Ceará, Brazil \\ d Veterinary Faculty, State University of Ceará, Fortaleza, Ceará, Brazil \\ e São Vicente Unit, Campus of Litoral Paulista, Paulista State University (UNESP), São Paulo, Brazil
}

\section{A R T I C L E I N F O}

\section{Article history:}

Received 18 June 2017

Received in revised form

1 August 2017

Accepted 20 August 2017

Available online 23 August 2017

\section{Keywords:}

Sea anemone

Bunodosoma caissarum

Isolated perfused kidney

Envenomation

Prostaglandin

Endothelin

\begin{abstract}
A B S T R A C T
Sea anemones contain a variety of interesting biologically active compounds, including some potent toxins. PLA $\mathrm{A}_{2}$ from Bunodosoma caissarum, a sea anemone endemic in the Brazilian southern coast, has shown renal alterations on isolated kidney. The aim of this study was to evaluate the renal and vascular effects of B. caissarum crude extract (BcE) on isolated perfused kidney and arteriolar mesenteric bed, as well the involvement of prostaglandins and endothelin. BcE did not show any effect on arteriolar mesenteric bed, but increased perfusion pressure, renal vascular resistance, urinary flow, glomerular filtration rate and decreased the percentage of sodium tubular transport on isolated perfused kidney. Indomethacin blocked the renal effects induced by $\mathrm{BcE}$ and tezosentan only partially blocked these effects. These results demonstrate the effects of BcE on kidney in situ, suggesting the involvement of prostaglandins and endothelin.
\end{abstract}

() 2017 Elsevier Ltd. All rights reserved.

\section{Introduction}

Several types of land animals produce natural toxins that are harmful to humans. In marine/aquatic environments, people have been injured by aquatic animals in various situations (Mizuno et al., 2012). Cnidarians are the oldest extant lineage of venomous animals. Using specialized penetrating nematocysts, cnidarians inject the nematocyst content or "venom" to capture prey and as defense against predators. These venoms contain enzymes, potent poreforming toxins, and neurotoxins, which trigger toxic and immunological reactions in the envenomated organism. In addition, certain cnidarian venoms contain or induce the release of vasodilatory biogenic amines in the host, such as serotonin, and histamine, accelerating the pathogenic effects of other venom enzymes and porins. The cnidarian attack/defense mechanism is fast and efficient, and massive envenomation of humans may result in

\footnotetext{
* Corresponding author.

E-mail address: robertajeanebj@gmail.com (R.J.B. Jorge).
}

death, in some cases within a few minutes to an hour after venom inoculation (Jouiaei et al., 2015).

Bunodosoma caissarum (Fig. 1), a sea anemone of the Cnidaria phylum, is found only in Brazilian coastal waters. Its venom has cytolytic, hemolytic, neurotoxic and cardiotoxic actions (Martins et al., 2009). Some components of this venom such as Bcs I (hemolytic toxin) (Oliveira et al., 2006a), BcIV (sodium channel toxin) (Oliveira et al., 2006b) and PLA 2 (Martins et al., 2009), BcsTx3 (potassium channel blocker) (Orts et al., 2013), have been studied regarding their biological effects, but some toxic effects of B. caissarum crude extract are still unknown.

Some venoms or their components are highly toxic for humans and can rarely cause multiple-organ failure and lethal shock (Mizuno et al., 2012). Acute Kidney Injury (AKI) has been reported after sea anemone envenomation (Mizuno et al., 2000). In previous studies, our research group showed the renal alterations caused by $\mathrm{PLA}_{2}$ from $B$. caissarum. Aiming at a better understanding of these vascular and renal effects of $B$. cainassum crude extract, we evaluated the effects of its crude extract on isolated perfused kidney and 


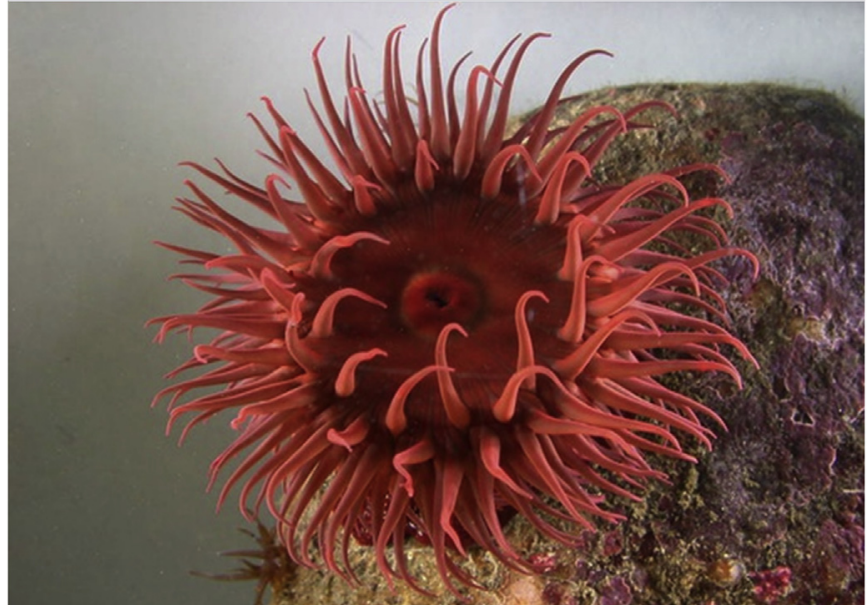

Fig. 1. Bunodosoma caissarum sea anemone. Alvaro E. Migotto. Anêmona-do-mar. Banco de imagens Cifonauta. Available in: http://cifonauta.cebimar.usp.br/photo/3810/ Access in: 2017-08-01

arteriolar mesenteric bed, as well as the involvement of prostaglandins and endothelin in its effect.

\section{Materials and methods}

\subsection{Bunodosoma caissarum crude extract and drugs}

Sixty specimens of $B$. caissarum (Fig. 1; weighing approximately $13 \mathrm{~g}$ each) were collected during periods of low tide by free diving at different rocky shores of the São Vicente Channel on the southern coast of Sao Paulo, Brazil. The animals were transported alive and starved in an aquarium for $72 \mathrm{~h}$ to eliminate any contents of the gastrovascular cavity. The animals' tentacles were removed, immediately immersed in an ice-cold aqueous solution of $0.1 \%$ trifluoroacetic acid solution (TFA) and submitted to three cycles of freezing and unfreezing. After the last cycle, the solution was centrifuged, the supernatant was recovered and filtered through a $0.45-\mu \mathrm{m}$ filter, followed by a second ultrafiltration through a 0.22 $\mu \mathrm{m}$ filter. The protein from the crude extract was obtained by acid precipitation using a $10 \%$ TFA solution. The acid precipitation was performed at $4{ }^{\circ} \mathrm{C}$ and the resulting solution was centrifuged. Then, the protein pellet was dissolved in water until complete dissolution was attained and then lyophilized (Martins et al., 2009).

Indomethacin was purchased from Sigma Chemical (MO-USA) and diluted in $5 \%$ sodium bicarbonate. Phenylephrine (Phe) was purchased from Sigma (St Louis, MO) and freshly diluted in the perfusion solution on the day of experiments. Tezosentan was generously provided by Actelion Pharmaceuticals (Basel, Switzerland).

\subsection{Isolated perfused kidney}

Adult male Wistar rats (240-300) were fasted for $24 \mathrm{~h}$ with free access to water. The rats were anesthetized with sodium pentobarbitone $(50 \mathrm{mg} / \mathrm{kg}$, i.p) and after careful dissection of the right kidney; the right renal artery was cannulated via the mesenteric artery without interrupting the blood flow as described by Bowman (1970) and modified by Fonteles et al. (1983). The perfusate consisted of a modified Krebs-Henseleit solution (MKHS) consisting of (in mM): $114.00 \mathrm{NaCl}, 4.96 \mathrm{KCl}, 1.24 \mathrm{KH}_{2} \mathrm{PO}_{4}, 0.5 \mathrm{MgSO}_{4} .7 \mathrm{H}_{2} \mathrm{O}, 2.10$ $\mathrm{CaCl}_{2}$ and $24.99 \mathrm{NaHCO}_{3}$. Bovine serum albumin (BSA $6 \mathrm{~g} \%$; fraction $\mathrm{V})$, urea $(0.075 \mathrm{~g})$, inulin $(0.075 \mathrm{~g})$ and glucose $(0.15 \mathrm{~g})$ were added to the solution, resulting in a final perfusate volume of $100 \mathrm{~mL}$. The $\mathrm{pH}$ was adjusted to 7.4. In each experiment, $100 \mathrm{~mL}$ of MKHS were recirculated for $120 \mathrm{~min}$. The perfusion pressure (PP) was measured at the tip of the stainless steel cannula in the renal artery. Urine and perfusate samples were collected at 10 min-intervals for analysis of sodium, potassium and chloride levels by ion-selective electrodes (RapidChem 744, Bayer Diagnostic, UK); inulin, as described by Walser et al. (1955) and modified by Fonteles et al. (1983); and osmolality, which was measured in a vapor pressure osmometer (Wescor $5100 \mathrm{C}$, USA). BcE ( $3 \mu \mathrm{g} / \mathrm{mL}$ ) was added to system $30 \mathrm{~min}$ after the beginning of each perfusion. Indometacin (IND $-10 \mu \mathrm{g} / \mathrm{mL}$ ) and Tezosentan (TZN $-3 \mu \mathrm{g} / \mathrm{mL}$ ) were added to system $30 \mathrm{~min}$ before the $\mathrm{BcE}(3 \mu \mathrm{g} / \mathrm{mL} ; \mathrm{n}=6)$. The perfusion pressure $(\mathrm{PP})$, renal vascular resistance (RVR), urinary flow (UF), glomerular filtration rate (GFR), the percentage of sodium $\left(\% \mathrm{TNa}^{+}\right)$, potassium $\left(\% \mathrm{TK}^{+}\right)$ and chloride $\left(\% \mathrm{Cl}^{-}\right)$tubular transport were determined. The results were compared to the internal control group, at 30 min early in each experiment $(n=6)$. This study was approved by the Ethics Committee on Animal Research (CEPA) of the Federal University of Pernambuco (Permit Number: 129/15).

\subsection{Isolated perfused arteriolar mesenteric bed}

The perfusion was performed following the descriptions of McGregor (1965). Briefly, Wistar rats, weighing 280-350 g were anesthetized with sodium pentobarbitone $(50 \mathrm{mg} / \mathrm{kg}$ of body weight). After opening the abdomen, the pancreatic-duodenal, ileum-colic, and colic branches of the superior mesenteric artery were tied. Then, the superior mesenteric artery was cleaned of surrounding tissue and cannulated using a polyethylene tube (PE20). The intestine was separated from the mesenteric bed by dissecting close to the intestinal border of the mesentery. The mesenteric bed was perfused with Krebs solution containing: $114.0 \mathrm{mM}$ of $\mathrm{NaCl} ; 4.96 \mathrm{mM}$ of $\mathrm{KCl} ; 1.24 \mathrm{mM}$ of $\mathrm{KH}_{2} \mathrm{PO}_{4} ; 0.5 \mathrm{mM}$ of $\mathrm{MgSO}_{4} .7 \mathrm{H}_{2} \mathrm{O} ; 24.99 \mathrm{mM}$ of $\mathrm{NaHCO}_{3} ; 2.10 \mathrm{mM}$ of $\mathrm{CaCl}_{2} .2 \mathrm{H}_{2} \mathrm{O}$; and $3.60 \mathrm{mM}$ of glucose. The perfusion solution was kept warm at $37{ }^{\circ} \mathrm{C}$ and the mesenteric bed was perfused by a constant flow $(4 \mathrm{~mL} / \mathrm{min})$ and variable perfusion pressure was measured at $80 \mathrm{~min}$ after the equilibration period. In this system, the direct vascular effects of $\mathrm{BcE}(10 \mu \mathrm{g} / \mathrm{mL} / \mathrm{min}$.; $\mathrm{n}=6)$, infused at a constant rate $(0.1 \mathrm{~mL} / \mathrm{min})$, were assessed and compared to the infusion of the vehicle alone at the same rate.

\subsection{Statistical analysis}

Results are shown as mean \pm S.E.M of six experiments for each group. Differences between groups were compared by using Student's t-test or analysis of variance (ANOVA) with significance set at $5 \%$.

\section{Results}

B. caissarum crude extract caused increased perfusion pressure (PP; Fig. 2A) and renal vascular resistance (RVR; Fig. 2B) at 60 and 90 min, urinary flow (UF; Fig. 2C) at 90 and $120 \mathrm{~min}$, and glomerular filtration rate (GFR; Fig. 2D) at $120 \mathrm{~min}$ on isolated kidney. The percentage of sodium tubular transport decreased $\left(\% \mathrm{TNa}^{+}\right.$; Fig. 2E) and no alterations were observed in the percentage of chloride (\% $\left.\mathrm{TCl}^{-}\right)$and potassium (\% $\left.\mathrm{TK}^{+}\right)$tubular transport on isolated kidney. Indomethacin caused significant decrease in glomerular filtration rate at $60 \mathrm{~min}$ and blocked the renal effects caused by BcE on all the evaluated parameters, when administrated 30 min before BcE. The increase in PP, RVR, UF and GFR were completely reversed (Figs. 2A and 1D). Indomethacin also blocked the effects of $\mathrm{BcE}$ on the percentage of sodium tubular transport (Fig. 2E). 

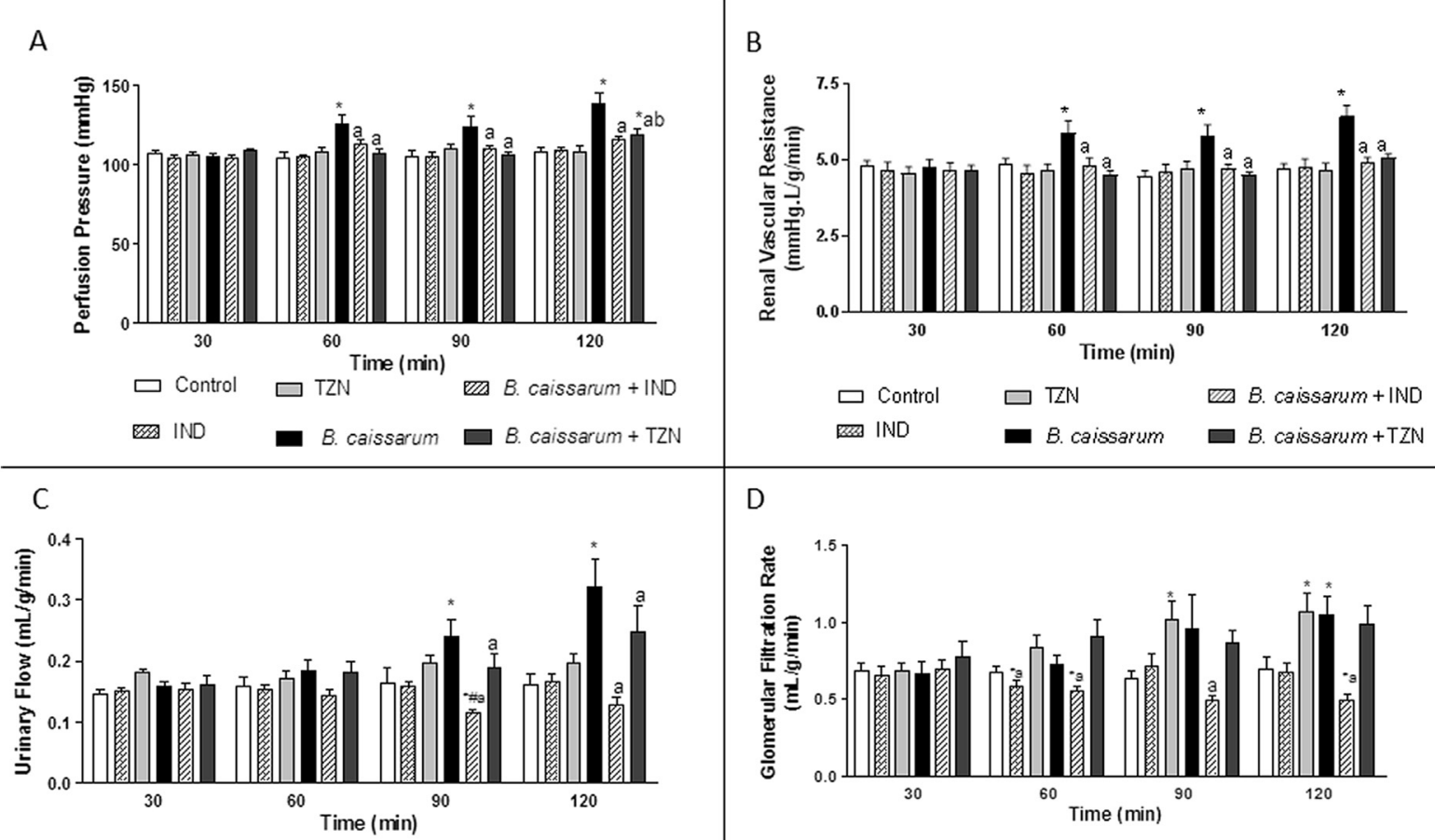

D
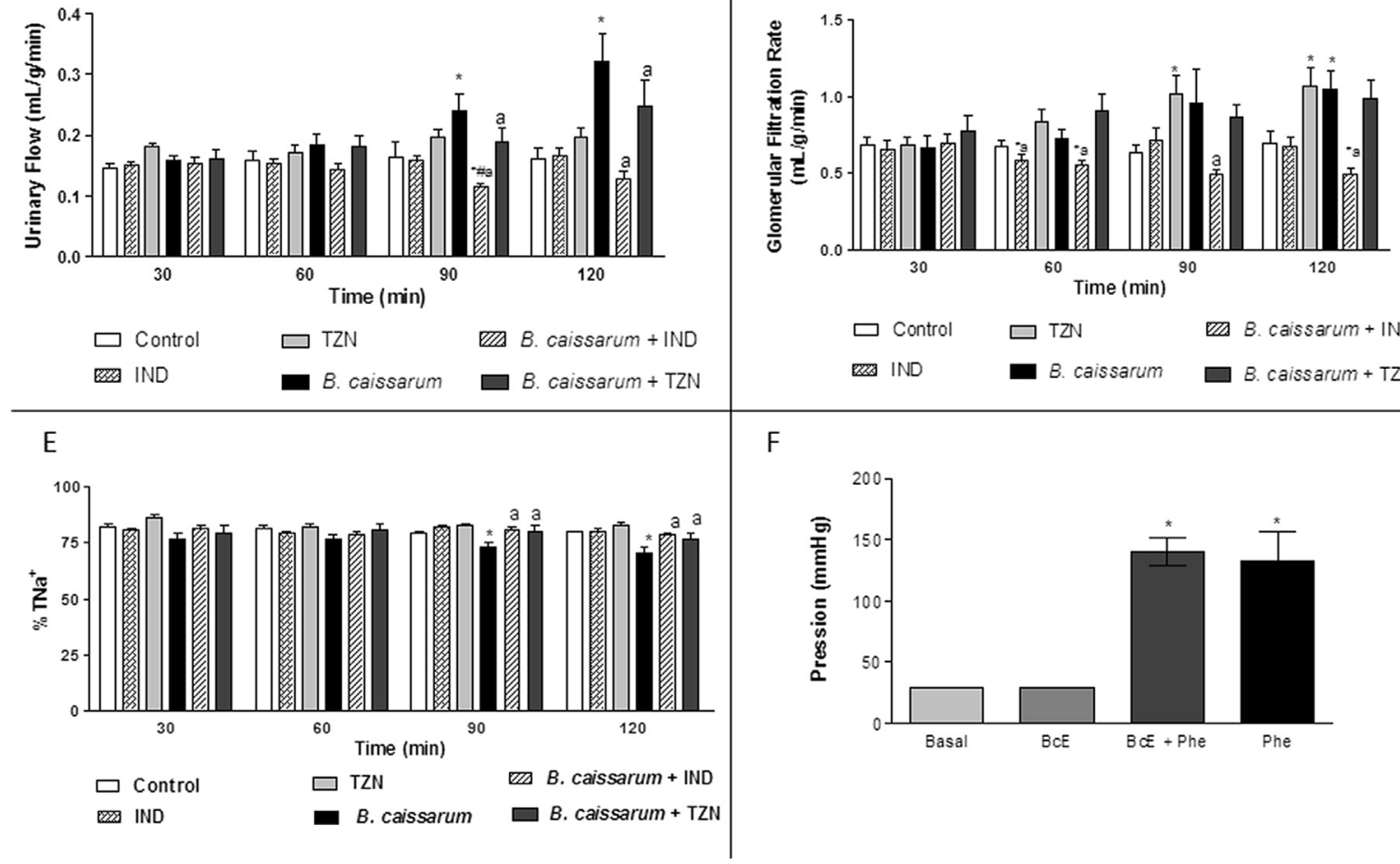

$$
\begin{array}{lll}
\square \text { Control } & \square \text { TZN } & \square \text { B. caissarum + IND } \\
\text { IND } & \square \text { B. caissarum } & \square \text { B. caissarum + TZN }
\end{array}
$$

F

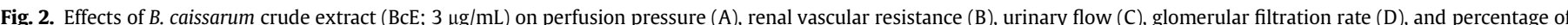

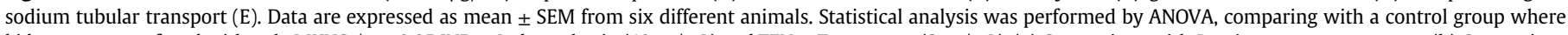

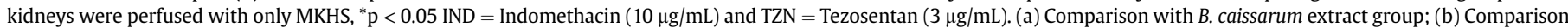

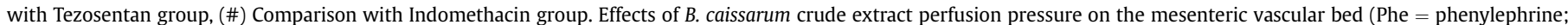

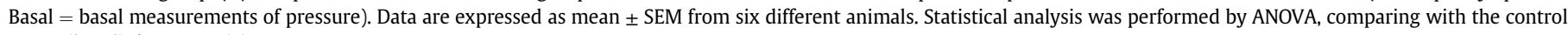
group (basal), ${ }^{*} \mathrm{p}<0.05(\mathrm{~F})$.

$\mathrm{BcE}(3 \mu \mathrm{g} / \mathrm{mL} / \mathrm{min})$ did not increase the perfusion pressure on the mesenteric vascular bed. The perfusion pressure varied from control values $(\mathrm{PP}=29.33 \pm 0.17 \mathrm{mmHg})$ to $(29.20 \pm 0.26 \mathrm{mmHg})$ after BcE infusion. The mesenteric blood vessels were contracted in the presence of phenylephrine (PhePP $=140.30 \pm 11.86^{*} \mathrm{mmHg}$ ) (Fig. 2F).

\section{Discussion}

Previously, our research group demonstrated the renal alterations of $\mathrm{PLA}_{2}$ on isolated perfused kidney, which increased the PP, RVR, urinary flow, glomerular filtration rate, and sodium, potassium and chloride excretion. The crude extract also showed increase on PP, RVR, UF and GFR, but decreased the \%TNa ${ }^{+}$and did not alter any other electrolytes transport. PLA $A_{2}$ from $B$. caissarum also did not show any effect on the perfusion pressure on the mesenteric vascular bed (Martins et al., 2009), as well its crude extract. This similarity on effects suggests the PLA 2 is partly responsible for these effects of the crude extract.

Indomethacin and tezosentan were used in order to evaluate the possible role of cyclooxygenase and endothelin on the renal changes induced by BcE. Indomethacin caused significant decrease in glomerular filtration rate at $60 \mathrm{~min}$ and blocked the renal effects caused by BcE on all the evaluated parameters, when administrated $30 \mathrm{~min}$ before BcE. This result suggests that the increase in renal PP and in RVR, previously observed in isolated perfused rat kidney, did not occur due to its direct action on renal vasculature. As an explanation, BcE might have promoted the release of substances synthesized by renal cells, such as prostaglandins, cytokines, bradykinin, complement fractions, platelet-activating factor (Barraviera et al., 1995; Facó et al., 2003) and endothelin (Chen et al., 2002). The blockage exerted by indomethacin treatment 
showed that prostaglandins were important mediators of BcE renal effects.

ET1 is major renal isoform produced by and acting on the mesangial cell (MC) and numerous stimuli modulate MC ET1 gene Transcription, including vasoactive substances, growth factors, cytokines, G protein-coupled receptor agonists (Sorokin and Kohan, 2003) and snake venom myotoxin (Barbosa et al., 2006). Infusion of exogenous ET1 reduces renal plasma flow and glomerular filtration rates and increases renal vascular resistance. These effects are partially or completely prevented by selective and non-selective endothelin receptor antagonists (Cheng and Harris, 2004; Sorokin and Kohan, 2003).

In the present work, we tested the effects of tezosentan, an ET-1 competitive receptor antagonist with high affinity to both ETA and ETB receptors with greater potency for the ETA subtype (Clozel et al., 1999). Tezosentan alone ( $3 \mu \mathrm{g} / \mathrm{mL})$ caused no alterations in renal physiology. It partially blocked the renal effects caused by BcE. Our results demonstrated that endothelin is also an important mediator in renal alterations induced by BcE, which could be caused by mesangial lysis or glomerular epithelial damage.

Indomethacin and Tezosentan blocked the renal alterations promoted by BcE. Cyclooxygenase activity can be stimulated by ET1 , resulting primarily in the increase in $\mathrm{PGE}_{2}$ and slight increase in thromboxane $A_{2}$ via $E_{A}$ receptor induction of $\mathrm{PLA}_{2}$ and $\mathrm{COX}-2$. These effects could explain the partial blocking of tezosentan on renal alterations induced by BcE (Fukunaga et al., 1996).

Swimmers, surfers, divers, and fishermen are exposed to envenomation syndromes induced by Atlantic cnidarian. The therapy used to treat sea anemone envenomation is vinegar (5\% acetic acid) and oral analgesics such as ibuprofen, acetaminophen, or acetylsalicylic acid are drugs of choice (Burnett, 2009; Hornbeak and Auerbach, 2017). In this work, the results suggest that renal alterations caused by $B$. caissarum venom could be blocked by cyclooxygenase inhibitors.

In conclusion, the effects on isolated kidney are probably determined by the release of renal prostaglandins and endothelin.

\section{Transparency document}

Transparency document related to this article can be found online at http://dx.doi.org/10.1016/j.toxicon.2017.08.019.

\section{References}

Barbosa, P.S., Martins, A.M., Alves, R.S., Amora, D.N., Martins, R.D., Toyama, M.H., Havt, A., Nascimento, N.R., Rocha, V.L., Menezes, D.B., Fonteles, M.C., Monteiro, H.S., 2006. The role of indomethacin and tezosentan on renal effects induced by Bothrops moojeni Lys49 myotoxin I. Toxicon 47 (8), 831-837.

Barraviera, B., Coelho, K.Y., Curi, P.R., Meira, D.A., 1995. Liver dysfunction in patients bitten by Crotalus Durissus terrificus (Laurenti, 1768) snakes in Botucatu (State of Sao Paulo, Brazil). Rev. Inst. Med. Trop. Sao Paulo 37 (1), 63-69.

Bowman, R.H., 1970. Gluconeogenesis in the isolated perfused rat kidney. J. Biol. Chem. 245, 1604-1612.

Burnett, J.W., 2009. Treatment of Atlantic cnidarian envenomations. Toxicon 54, 1201-1205.

Chen, B., Jiang, D., Tang, L., 2002. Effects of advanced glycation end products and hypoxia on endothelin-1 secretion by bovine retinal microvascular pericytes. Yan Ke Xue Bao 18 (2), 84-86.

Cheng, H.F., Harris, R.C., 2004. Cyclooxygenases, the kidney, and hypertension. Hypertension 43 (3), 525-530 (Review).

Clozel, J.P., Veniant, M.M., Qiu, C., Sprecher, U., Wolfgang, R., Fischli, W., 1999. Renal vascular and biochemical responses to systemic renin inhibition in dogs at low renal perfusion pressure. J. Cardiovasc Pharmacol. 34 (5), 674-682.

Facó, P.E., Havt, A., Barbosa, P.S., Nobre, A.C., Bezerra, G.P., Menezes, D.B., Fonteles, M.C., Lopes-Ferreira, M., Monteiro, H.S., 2003. Effects of Thalassophryne nattereri fish venom in isolated perfused rat kidney. Toxicon 42 (5), 509-514.

Fonteles, M.C., Cohen, J.J., Black, A.J., Wertheim, S.J., 1983. Support of renal kidney function by long-chain fatty acids derived from renal tissue. Am. J. Physiol. 244, 235-246.

Fukunaga, M., Fujiwara, Y., Ochi, S., Yokoyama, K., Shoji, T., Fukuhara, Y., Orita, Y., Kamada, T., Badr, K.F., Ueda, N., 1996. Mechanism of induction of prostaglandin E2 production by endothelin 1 in cultured rat mesangial cells. Exp. Nephrol. 4 (6), 340-349.

Hornbeak, K.B., Auerbach, P.S., 2017. Marine envenomation. Emerg. Med. Clin. North Am. 35 (2), 321-337.

Jouiaei, M., Yanagihara, A.A., Madio, B., Nevalainen, T.J., Alewood, P.F., Fry, B.G., 2015. Ancient venom systems: a review on Cnidaria toxins. Toxins (Basel) 7 (6), 2251-2271

Martins, R.D., Alves, R.S., Martins, A.M., Barbosa, P.S., Evangelista, J.S., Evangelista, J.J., Ximenes, R.M., Toyama, M.H., Toyama, D.O., Souza, A.J., Orts, D.J., Marangoni, S., de Menezes, D.B., Fonteles, M.C., Monteiro, H.S., 2009. Purification and characterization of the biological effects of phospholipase $A(2)$ from sea anemone Bunodosoma caissarum. Toxicon 54 (4), 413-420.

McGregor, D.D., 1965. The effect of sympathetic nerve stimulation on vasoconstrictor responses in perfused mesenteric blood vessels of the rat. J. Physiol. 177, $21-30$.

Mizuno, M., Ito, Y., Morgan, B.P., 2012. Exploiting the nephrotoxic effects of venom from the sea anemone, Phyllodiscus semoni, to create a hemolytic uremic syndrome model in the rat. Mar. Drugs 10 (7), 1582-1604.

Mizuno, M., Nishikawa, K., Yuzawa, Y., Kanie, T., Mori, H., Araki, Y., Hotta, N., Matsuo, S., 2000. Acute renal failure after a sea anemone sting. Am. J. Kidney Dis. 36 (2), E10.

Oliveira, J.S., Zaharenko, A.J., De Freitas, J.C., Konno, K., De Andrade, S.A., Portaro, F.C., Richardson, M., Sant'anna, O.A., Tambourgi, D.V., 2006a. Caissarolysin I (Bcs I), a new hemolytic toxin from the Brazilian sea anemone Bunodosoma caissarum: purification and biological characterization. Biochim. Biophys. Acta 1760 (3), 453-461.

Oliveira, J.S., Zaharenko, A.J., Ferreira-Junior, W.A., Konno, K., Shida, C.S., Richardson, M., Lucio, A.D., Beirao, P.S., De Freitas, J.C., 2006b. BcIV, a new paralyzing peptide obtained from the venom of the sea anemone Bunodosoma caissarum. A comparison with the $\mathrm{Na}+$ channel toxin BcIII. Biochim. Biophys. Acta 1764 (10), 1592-1600.

Orts, D.J., Moran, Y., Cologna, C.T., Peigneur, S., Madio, B., Praher, D., Quinton, L., De Pauw, E., Bicudo, J.E., Tytgat, J., de Freitas, J.C., 2013. BcsTx3 is a founder of a novel sea anemone toxin family of potassium channel blocker. FEBS J. 280 (19), 4839-4852.

Sorokin, A., Kohan, D.E., 2003. Physiology and pathology of endothelin-1 in renal mesangium. Am. J. Physiol. Ren. Physiol. 285 (4), F579-F589.

Walser, M., Davidson, D.G., Orloff, J., 1955. The renal clearance of alkali stable inulin. J. Clin. Investig. 34, 1520-1523. 